\title{
Direct visualisation of carbon dioxide adsorption in gate-opening zeolitic imidazolate framework ZIF-7†
}

Cite this: J. Mater. Chem. A, 2014, 2 , 620

Received 3rd October 2013

Accepted 26th November 2013

DOI: 10.1039/c3ta13981f

www.rsc.org/MaterialsA

\author{
Pu Zhao, ${ }^{a}$ Giulio I. Lampronti, ${ }^{a}$ Gareth O. Lloyd, $\dot{t}^{\mathrm{b}}$ Emmanuelle Suard ${ }^{\mathrm{c}}$ \\ and Simon A. T. Redfern ${ }^{\star a}$
}

The crystal structures of zeolitic imidazolate framework 7 (ZIF-7) under various $\mathrm{CO}_{2}$ pressures were studied by high-resolution neutron powder diffraction. $\mathrm{CO}_{2}$ adsorption in $\mathrm{ZIF}-7$ is visualised and demonstrated to be primarily controlled by the benzimidazolate ligands via a gate-opening mechanism. Our results highlight the importance of pressure on the $\mathrm{CO}_{2}$ adsorption and the related structural framework responses in ZIF-7.

Zeolitic imidazolate frameworks (ZIFs) are important members of the family of metal organic framework (MOF) materials. They can act as host frameworks for $\mathrm{CO}_{2}$ adsorption, with important potential applications in low-temperature $\mathrm{CO}_{2}$ separation and sequestration technology. ZIFs are so-called because of their zeolite-like structures, but instead of aluminosilicate frameworks they are composed of transition metal cations coordinated by imidazolate ligands. There has been considerable interest in ZIFs' structure-property relations and the influences of modifications of its zeolite-like structures. ZIF-7 ( $\mathrm{Zn}(\mathrm{PhIm})_{2}$, PhIm = benzimidazolate) is a typical ZIF with sodalite (SOD) framework topology. ${ }^{\mathbf{1} 2}$ Due to the phenyl group in its benzimidazolate ligands, the structure and properties of ZIF-7 are distinct from its more commonly-considered cousin, ZIF-8 (ref. 1 and 3-10) and aluminosilicate sodalites which share similar cubic crystalline topology. ZIF-7 has previously been shown to

${ }^{a}$ Department of Earth Sciences, University of Cambridge, Downing Street, Cambridge, CB2 3EQ, UK. E-mail: satr@cam.ac.uk

${ }^{b}$ Department of Chemistry, University of Cambridge, Lensfield Road, Cambridge, CB2 $1 E W, U K$

'Institut Laue-Langevin, BP 156, 6, rue Jules Horowitz, Grenoble, Cedex 9, 38042, France

$\dagger$ Electronic supplementary information (ESI) available: Synthesis and characterisation of D-ZIF-7 sample, neutron powder diffraction details, structure refinement methods and illustrations of D-ZIF-7 $\left(\mathrm{CO}_{2}\right)$ structures. CCDC 973356-973359. For ESI and crystallographic data in CIF or other electronic format see DOI: 10.1039/c3ta13981f

\$ Current address: Institute of Chemical Sciences, School of Engineering and Physical Sciences, William Perkin Building, Heriot-Watt University, Edinburgh, EH14 4AS, UK. exhibit gate-opening behaviour during $\mathrm{CO}_{2}$ sorption. ${ }^{\mathbf{1 1 2}}$ Its framework flexibility was shown to be related to a reversible structural phase transition upon loading and unloading of $\mathrm{CO}_{2}$ guest molecules into the nanoporous host structure. ${ }^{13}$ Theoretical calculations indicate that the benzimidazolate ligands in ZIF-7 may be the key to its framework flexibility and related unique $\mathrm{CO}_{2}$ sorption behaviour. ${ }^{11,12,14}$

If we are to develop a better understanding of the $\mathrm{CO}_{2}$ adsorption process in ZIF-7 and the functionality of the benzimidazolate ligands, it is necessary to elucidate the guest molecular configurations and framework response of ZIF-7 during $\mathrm{CO}_{2}$ incorporation, ideally by direct crystal structural study. To this end, we have employed high-resolution neutron powder diffraction to monitor the structural effects associated with $\mathrm{CO}_{2}$ adsorption in ZIF-7 under industrial $\mathrm{CO}_{2}$ pressures. Our results show the dominant role of benzimidazolate ligands in the $\mathrm{CO}_{2}$ adsorption process in ZIF-7. They also reveal the importance of gas loading pressure on the guest-host relationships in the ZIF-7 $\left(\mathrm{CO}_{2}\right)$ system.

Deuterated ZIF-7 (D-ZIF-7) powder $(0.14 \mathrm{~g})$ was prepared based on the procedure described previously, but employing deuterated benzimidazole as reagent. ${ }^{12}$ The sample was placed into an aluminium can with gas loading system. Neutron powder diffraction measurements were performed under $p \mathrm{CO}_{2}$ $=0,50,100,200 \mathrm{kPa}$ at $300 \mathrm{~K}$ using high-resolution neutron powder diffractometer D2B at the Institut Laue-Langevin. Before data collection, in order to remove all possible residing guest molecules, the sample was heated from 300 to $393 \mathrm{~K}$ at a rate of $1 \mathrm{~K} \mathrm{~min}^{-1}$ under vacuum; the temperature was then kept at $393 \mathrm{~K}$ for 2 hours before cooling to $300 \mathrm{~K}\left(1 \mathrm{~K} \mathrm{~min}^{-1}\right)$ for neutron diffraction measurements. The crystal structure of guest-free D-ZIF-7 was refined by the Rietveld method ${ }^{15,16}$ using Topas $4.1,{ }^{17}$ using the hydrogenated ZIF-7 structure given by Yaghi et al. as the starting model. ${ }^{1}$ The determination of the location of $\mathrm{CO}_{2}$ molecules in the D-ZIF-7 $\left(\mathrm{CO}_{2}\right)$ structure under $p \mathrm{CO}_{2}=50 \mathrm{kPa}$ was carried out using Fourier difference maps generated by GSAS. ${ }^{18,19}$ Further input from DFT calculation indicated that two $\mathrm{CO}_{2}$ adsorption sites are most reasonable for 
Rietveld refinement of the internal structure of D-ZIF-7 $\left(\mathrm{CO}_{2}\right)$ under $p \mathrm{CO}_{2}=50,100,200 \mathrm{kPa}$. In particular, the modelling of D-ZIF-7 $\left(\mathrm{CO}_{2}\right)$ structure $\left(p \mathrm{CO}_{2}=100 \mathrm{kPa}\right)$ was carried out by combined-Rietveld refinement on two neutron diffraction datasets obtained using different incident beam wavelengths $\lambda=1.5946$ and $2.3909 \AA$ A. Further experimental details are provided in the ESI. $\dagger$

Both $\mathrm{CO}_{2}$ adsorption sites reside in the small cavities formed by the benzimidazolate ligands in the six-membered rings of zinc atoms (Fig. 1). They are designated A and B according to their host cavity features. Cavity A has the largest void in ZIF-7 and has previously been proposed as the primary gas adsorption site. ${ }^{\mathbf{1 1}}$ Its zinc ring plane is perpendicular to the 3 -fold rotoinversion axis and the benzimidazolates point towards the axis to form a rhombohedral cage. Cavity B, on the other hand, has lower point symmetry and is open. Comparing it with Cavity A, one notes that the two opposing benzimidazolates in Cavity B point away from the cavity axis and the six-membered ring formed by the zinc atoms is distorted. The Wycoff multiplicities of cavities A and B in ZIF-7 structure are 6 and 18, respectively. There is no significant $\mathrm{CO}_{2}$ adsorption either around zinc four-membered rings or in the topological beta-cage of ZIF-7. The $\mathrm{CO}_{2}$ adsorption sites in ZIF-7 share certain similarities with those in ZIF-8: the dominant gas adsorption sites in ZIF-8 are in a Cavity A type pores formed by methylimidazolates. ${ }^{20-23}$ In ZIF-7 the benzimidazolate ligand the controlling factor on $\mathrm{CO}_{2}$ adsorption.

$\mathrm{CO}_{2}$ adsorption site preferences revealed by our experimental data are in excellent agreement with recent simulation results from Morris et al. ${ }^{14}$ Simulated binding energies indicate Cavity B is more energetically preferable than Cavity A for $\mathrm{CO}_{2}$ adsorption. Experimental $\mathrm{CO}_{2}$ occupancies (Table 1) confirm this adsorption preference. This is due to the geometry differences between the two cavities. Since Cavity B is relatively open, it accommodates guest incorporation and transportation more readily. While one might anticipate small differences between the behaviour of hydrogenous ZIF-7 and deuterated ZIF-7, due to mass differences, the correspondence of our results with those of Morris et al. ${ }^{\mathbf{1 4}}$ indicates that such differences are not significant within the framework of this study.

In guest-free D-ZIF-7, the diameter of the largest guest-accessible window in Cavity A is $\sim 3 \AA$ A. Considering the Lennard-Jones

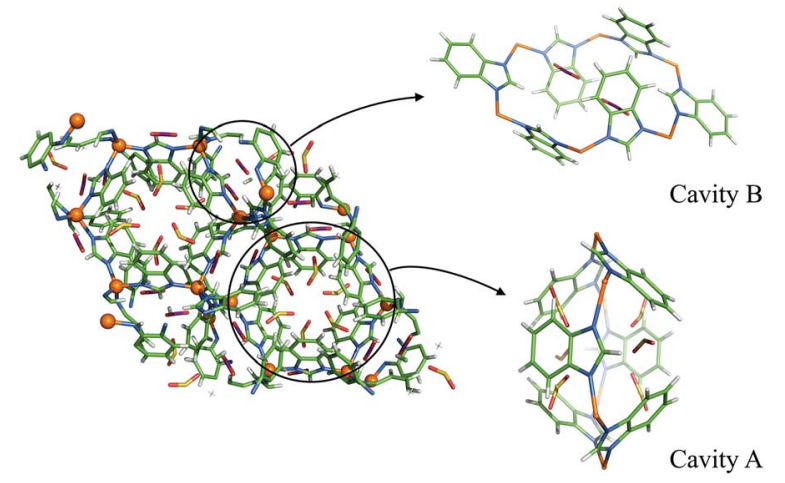

Fig. $1 \mathrm{D}-\mathrm{ZIF}-7\left(\mathrm{CO}_{2}\right)$ structure, $p \mathrm{CO}_{2}=50 \mathrm{kPa}$. Zn: orange, $\mathrm{C}$ : cyan, $\mathrm{N}$ : blue, $\mathrm{H} / \mathrm{D}$ : silver. $\mathrm{CO}_{2}$ : $\mathrm{C}$ in Cavity A yellow, in Cavity B purple; $\mathrm{O}$, red.
Table 1 Physical data of D-ZIF-7 $\left(\mathrm{CO}_{2}\right)$ structures under various $\mathrm{CO}_{2}$ pressures. (space group: $R \overline{3}$ )

\begin{tabular}{|c|c|c|c|c|c|}
\hline$p \mathrm{CO}_{2}[\mathrm{kPa}]$ & & 0 & 50 & 100 & 200 \\
\hline \multirow[t]{2}{*}{$\mathrm{CO}_{2}$ occupancy } & A & 0 & 0.35 & 0.26 & 0.25 \\
\hline & B & 0 & 0.53 & 0.68 & 0.68 \\
\hline $\begin{array}{l}\text { Calculated total } \mathrm{CO}_{2} \\
\text { uptake }\left[\mathrm{mmol} \mathrm{g}^{-1}\right]\end{array}$ & & 0 & 2.60 & 2.76 & 2.73 \\
\hline$a=b[\AA]$ & & 22.94 & 23.00 & 22.88 & 22.95 \\
\hline$c[\AA]$ & & 15.75 & 15.76 & 15.66 & 15.71 \\
\hline$V\left[\AA^{3}\right]$ & & 7178 & 7224 & 7098 & 7165 \\
\hline
\end{tabular}

collision diameter of $\mathrm{CO}_{2}(4.05 \AA),{ }^{24}$ it is very difficult for $\mathrm{CO}_{2}$ to enter into Cavity A via this window if the structure is static. The rotational freedom of the benzimidazolate ligands plays an important role in accommodating guest molecule transport and dynamics. ${ }^{11}$ There are a number of examples from the literature showing that the static crystal structure and dynamic radii of guest molecules do not always match..$^{25-29}$ Thus, it is reasonable that Cavity A has some adsorption capacity. Cavity B, on the other hand, has much larger guest accessibility than Cavity A. The benzimidazolates with phenyl group pointing away from the cavity axis open up to form a large channel (diameter $\sim 5-6 \AA$ ) for $\mathrm{CO}_{2}$ adsorption. The topological beta-cage of ZIF-7 plays little part in $\mathrm{CO}_{2}$ incorporation from both theoretical and experimental aspects; we attribute this to the strong steric effect from phenyl rings. It is worth noting that along with the increase of pressure, $\mathrm{CO}_{2}$ molecules tend to aggregate in Cavity B while leaving Cavity A relatively empty. This phenomenon is of interest for further investigation on the $\mathrm{CO}_{2}$ transportation in $\mathrm{ZIF}-7$; the direct $\mathrm{CO}_{2}$ transport route from Cavity A to B is via the beta-cage, however, $\mathrm{CO}_{2}$ transport barriers from Cavity A and B into beta-cage are very high, therefore the actual $\mathrm{CO}_{2}$ transport route is uncertain and expected to be influenced by the benzimidazolate ligands.

$\mathrm{A} \mathrm{CO}_{2}$-induced gate-opening process in D-ZIF-7 is indicated by our experimental results. Compared with the previous experimental $\mathrm{CO}_{2}$ adsorption isotherms, ${ }^{13,14}$ the calculated total $\mathrm{CO}_{2}$ uptake in our D-ZIF-7 $\left(\mathrm{CO}_{2}\right)$ structures (Table 1) suggests that at $p \mathrm{CO}_{2}=50 \mathrm{kPa}$ the D-ZIF-7 sample is nearly fully saturated with $\mathrm{CO}_{2}$. Examining our D-ZIF-7 structural results we notice that the unit cell expands when $\mathrm{CO}_{2}$ pressure increases from 0 to $50 \mathrm{kPa}$. The benzimidazolate ligands of both Cavity $\mathrm{A}$ and $\mathrm{B}$ rotate to open up those cavities for $\mathrm{CO}_{2}$ adsorption (Fig. 2). When the $\mathrm{CO}_{2}$ pressure increases from 50 to $100 \mathrm{kPa}$, the total amount of $\mathrm{CO}_{2}$ adsorbed increases. At this stage, although $\mathrm{CO}_{2}$ begins to flow into Cavity $\mathrm{B}$, the benzimidazolates at Cavity A continue to rotate to increase the accommodation space for more $\mathrm{CO}_{2}$ molecules to enter. Meanwhile, at Cavity B, the zinc six-membered ring becomes more distorted due to the movement of the ligands for gate-opening. It seems that the ligand movement in Cavity B induces an electrostatic field change in the cavity itself which helps to increase the affinity of $\mathrm{CO}_{2}$. The distortion of the zinc six-membered ring may be responsible for the subtle shrinkage in the unit cell dimensions.

At higher external $\mathrm{CO}_{2}$ pressure, from $p \mathrm{CO}_{2}=100$ to $200 \mathrm{kPa}$, the influence of external pressure on the $\mathrm{CO}_{2}$ adsorption and structural behaviour of ZIF-7 becomes crucial. Fig. 2c clearly 
a)

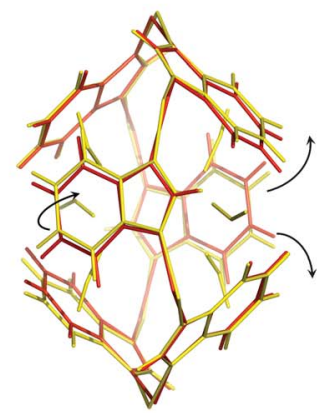

b)

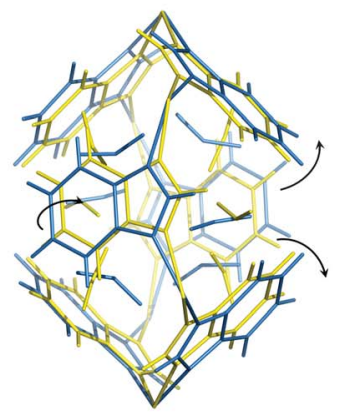

c)

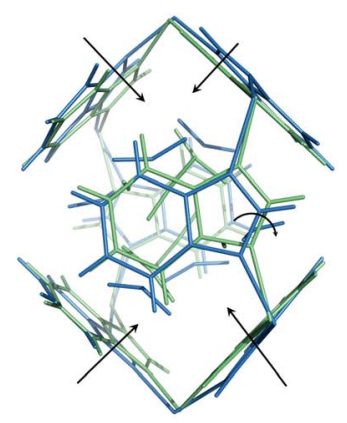

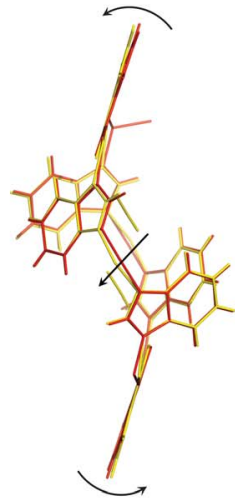
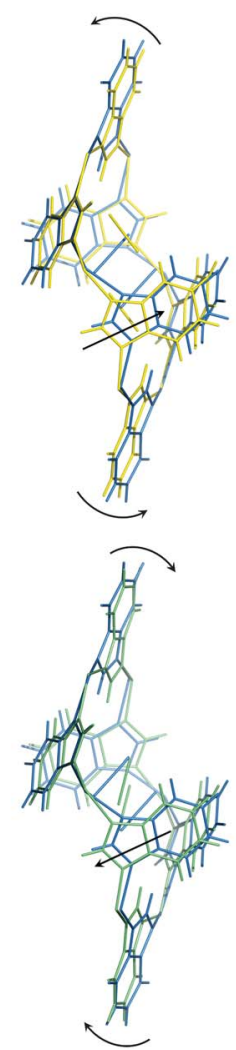

Fig. 2 Dynamic structural behaviours of Cavity A (left) and B (right) at $\mathrm{pCO}_{2}=$ (a) 0 (red) to 50 (yellow) $\mathrm{kPa}$; (b) 50 to 100 (blue) $\mathrm{kPa} ; 100$ to 200 (cyan) $\mathrm{kPa}$.

shows that Cavity A is squeezed by the external pressure instead of continuing to open up for internal $\mathrm{CO}_{2}$ adsorption in this pressure regime. At Cavity $\mathrm{B}$, the zinc six-membered ring becomes less distorted and ligands move in the opposite sense compared to that seen upon pressure change from 50 to 100 $\mathrm{kPa}$. This ligand movement induces anomalous unit cell expansion. For $\mathrm{CO}_{2}$ pressures from 100 to $200 \mathrm{kPa}$ the total $\mathrm{CO}_{2}$ uptake and $\mathrm{CO}_{2}$ occupancy hardly increase any further. This suggests that the extrusion of Cavity A by increasing pressure inhibits further $\mathrm{CO}_{2}$ adsorption and transportation to Cavity B. The effect of external $v s$. internal pressure also influences the $\mathrm{CO}_{2}$ locations as a function of $p \mathrm{CO}_{2}$. This is illustrated in Fig. 3, where both $\mathrm{CO}_{2}$ adsorption sites are seen to move into the centre of Cavity A and B upon increasing $p \mathrm{CO}_{2}$.
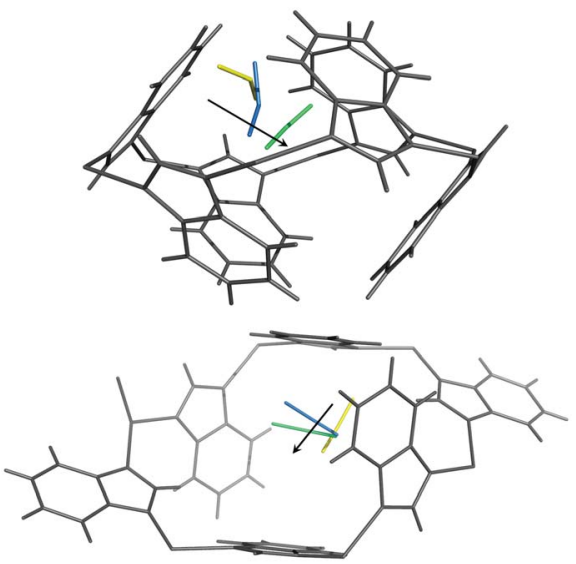

Fig. 3 The $\mathrm{CO}_{2}$ adsorption site at Cavity $\mathrm{A}$ (upper figure) and $\mathrm{B}$ (lower figure) at $\mathrm{pCO}_{2}=50$ (yellow), 100 (blue), 200 (cyan) kPa.

\section{Conclusions}

In summary, using high-resolution neutron powder diffraction, we have determined the $\mathrm{CO}_{2}$ adsorption geometry and site preference in ZIF-7. The results illustrate the importance of the benzimidazolate ligands in controlling the $\mathrm{CO}_{2}$ affinity and structural flexibility of ZIF-7. They also reveal the influence of pressure in the $\mathrm{CO}_{2}$ adsorption process in ZIF-7. This is of most importance in understanding the potential of these materials in gas storage and separation in industrial processes. We find that the gas adsorption properties of ZIF-7 depend upon a balance between the internal pressure of the guest molecule and the external gas pressure imposed at the higher range of pressures applied. We will explore the role of the latter in future studies of the structural response of ZIF-7 under different imposed pressures with a variety of guest molecules.

\section{Acknowledgements}

This work was supported by the Cambridge Commonwealth, European and International Trust; China Scholarship Council; University of Cambridge; the Herchel Smith Fund (Cambridge); Heriot-Watt University; UK Science and Technology Facilities Council; Institut Laue-Langevin. We thank Mr Rajkrishna Dutta for his DFT calculation.

\section{Notes and references}

1 K. S. Park, Z. Ni, A. P. Côté, J. Y. Choi, R. Huang, F. J. UribeRomo, H. K. Chae, M. O'Keeffe and O. M. Yaghi, Proc. Natl. Acad. Sci. U. S. A., 2006, 103, 10186-10191.

2 X. Huang, J. Zhang and X. Chen, Chin. Sci. Bull., 2003, 48, 1531-1534.

3 H. L. Jiang, B. Liu, T. Akita, M. Haruta, H. Sakurai and Q. Xu, J. Am. Chem. Soc., 2009, 131, 11302-11303.

4 S. A. Moggach, T. D. Bennett and A. K. Cheetham, Angew. Chem., Int. Ed., 2009, 48, 7087-7089.

5 G. Lu and J. T. Hupp, J. Am. Chem. Soc., 2010, 132, 7832-7833. 
6 K. W. Chapman, D. F. Sava, G. J. Halder, P. J. Chupas and T. M. Nenoff, J. Am. Chem. Soc., 2011, 133, 18583-18585.

7 D. Peralta, G. Chaplais, A. Simon-Masseron, K. Barthelet, C. Chizallet, A. A. Quoineaud and G. D. Pirngruber, J. Am. Chem. Soc., 2012, 134, 8115-8126.

8 W. Chaikittisilp, M. Hu, H. Wang, H. S. Huang, T. Fujita, K. C. W. Wu, L. C. Chen, Y. Yamauchi and K. Ariga, Chem. Commun., 2012, 48, 7259-7261.

9 S. Cao, T. D. Bennett, D. A. Keen, A. L. Goodwin and A. K. Cheetham, Chem. Commun., 2012, 48, 7805-7807.

10 L. Zhang, Z. Hu and J. Jiang, J. Am. Chem. Soc., 2013, 135, 3722-3728.

11 J. van den Bergh, C. Gücüyener, E. A. Pidko, E. J. Hensen, J. Gascon and F. Kapteijn, Chem.-Eur. J., 2011, 17, 8832-8840.

12 C. Gücüyener, J. van den Bergh, J. Gascon and F. Kapteijn, J. Am. Chem. Soc., 2010, 132, 17704-17706.

13 S. Aguado, G. Bergeret, M. P. Titus, V. Moizan, C. NietoDraghi, N. Bats and D. Farrusseng, New J. Chem., 2011, 35, 546-550.

14 W. Morris, N. He, K. G. Ray, P. Klonowski, H. Furukawa, I. N. Daniels, Y. A. Houndonougbo, M. Asta, O. M. Yaghi and B. B. Laird, J. Phys. Chem. C, 2012, 116, 24084-24090.

15 L. B. McCusker, R. B. Von Dreele, D. E. Cox, D. Louër and P. Scardi, J. Appl. Crystallogr., 1999, 32, 36-50.

16 R. A. Young, The Rietveld Method, Oxford University Press, 1995.

17 A. A. Coelho, Coelho Software, Brisbane, 2007.
18 B. H. Toby, J. Appl. Crystallogr., 2001, 34, 210-213.

19 A. C. Larson and R. B. Von Dreele, in Los Alamos National Laboratory Report LAUR, 1994, pp. 86-748.

20 J. Pérez-Pellitero, H. Amrouche, F. R. Siperstein, G. Pirngruber, C. Nieto-Draghi, G. Chaplais, A. SimonMasseron, D. Bazer-Bachi, D. Peralta and N. Bats, Chem.Eur. J., 2010, 16, 1560-1571.

21 H. Wu, W. Zhou and T. Yildirim, J. Am. Chem. Soc., 2007, 129, 5314-5315.

22 H. Wu, W. Zhou and T. Yildirim, J. Phys. Chem. C, 2009, 113, 3029-3035.

23 B. Assfour, S. Leoni and G. Seifert, J. Phys. Chem. C, 2010, 114, 13381-13384.

24 S. Matteucci, Y. Yampolskii, B. D. Freeman and I. Pinnau, in Materials Science of Membranes for Gas and Vapor Separation, John Wiley \& Sons, Ltd, 2006, pp. 1-47.

25 L. Dobrzańska, G. O. Lloyd, H. G. Raubenheimer and L. J. Barbour, J. Am. Chem. Soc., 2006, 128, 698-699.

26 P. K. Thallapally, G. O. Lloyd, J. L. Atwood and L. J. Barbour, Angew. Chem., Int. Ed., 2005, 44, 3848-3851.

27 T. Jacobs, G. O. Lloyd, J. A. Gertenbach, K. K. MüllerNedebock, C. Esterhuysen and L. J. Barbour, Angew. Chem., Int. Ed., 2012, 51, 4913-4916.

28 J. L. Atwood, L. J. Barbour, A. Jerga and B. L. Schottel, Science, 2002, 298, 1000-1002.

29 X. Zhao, B. Xiao, A. J. Fletcher, K. M. Thomas, D. Bradshaw and M. J. Rosseinsky, Science, 2004, 306, 1012-1015. 